\title{
Hasan Pekmezci ve Sanatı Üzerine
}

Arş. Gör. Dr. Zeliha Kayahan

\section{Özet}

1968 yılında Arifiye Öğretmen Okulu’na atanmasıyla profesyonel olarak sanat eğitimi hayatına başlamış olan ve günümüze kadar sanat/sanat eğitiminin içinde dinamik bir şekilde varlığın sürdüren Hasan Pekmezci, bu yıl sanat hayatının 50. yılını kutlamaktadır. Öğrenme ve öğretme dürtüsünün birlikteliğini hiçbir zaman taviz vermeden sürdüren Pekmezci, șüphesiz Çağdas Türk

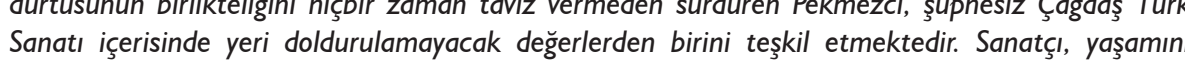
sanata, sanatıı da yaşamına dönüşürmüştür ve tüm değerlerini bu iki temel üzerine inşa etmiştir. Pekmezci için yaşamak da sanat da nefes almak demektir. Sanatçının "Yaşam Kısa Sanat Sonsuz" bașlıklı makalesini elinize aldığınızda sizi karşılayan "Yaşamak güzel șey be kardeşim!" ilk cümlesi bu düşünceyi tümüyle destekler niteliktedir. Eserlerine bakacak olursanız aynı bu cümlenin somut halin görmeniz mümkündür ve bizler biliyoruz ki hayatla ve sanatla mücadelesi hiç bitmemiș bir sanatçıdır

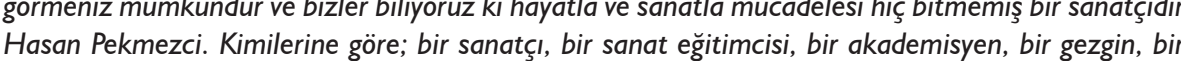
Hasan Pekmezci. Kimilerine göre; bir sanatçı, bir sanat eğitimcisi, bir akademisyen, bir gezgin, bir baba, bir eş, bir dost, bir arkadaş, bir destek, bir kaynak.. Bu çalışma Pekmezci'nin sahip olduğu tüm bu kimlikler ile yaşama dair ortaya koyduğu mücadelelere ve bu mücadeleler sonunda oluşturduğu eserlerine odaklanacaktır. Böylece yeni nesil sanatçı adaylarına nasıl yaşamak/ üretmek gerektiğine dair bir anahtar bilgi sunmak amaçlanmaktadır.

Anahtar Sözcükler: Çağdaş Türk Sanatı, Sanat, Hasan Pekmezci

\section{HASAN PEKMEZCI AND ON HIS ART}

\section{Abstract}

Hasan Pekmezci, whose professional art education started in the year 1968 after he was assigned to Arifiye Teacher's Training School and continues to exist dynamically within art/art education until today, celebrates the 50 th year of his life in art this year. Pekmezci, who continues the togetherness of learning and teaching motivation always without a sacrifice, is for sure constitutes one of the irreplaceable values in Contemporary Turkish Art. The Artist has turned his life to art and his art to his life, and built all his values on this two basis. For Pekmezci, both living and art mean to breathe. When you read the Artist's article with "Life is Short, Art is Forever" title, the first sentence you see which is "Life is beautiful fellas!" has the characteristics to completely support this opinion. If you review his works, it is possible to see the concrete form of this sentence, and we know that Hasan Pekmezci is an artist whose struggle with the life and art has never ended. According to some; an artist, an art educator, an academician, a traveler, a poet, an author, a father, a spouse, a friend, $a$ true friend a support, a source.. This study will focus on all those identities that Pekmezci has and true friend, a support, a source... This study will focus on all those identities that Pekmezci has and
the struggles he put forward about life and the works he create at the end of those struggles. Thus. it is aimed to offer a key knowledge to new generation artist candidates about how to live/produce.

Keywords: Contemporary Turkish Art, Art, Hasan Pekmezci 


\section{Giriş}

Shiller'e göre "Sanat, doğa'nın sağ elidir. Doğa bizi var etmiştir yalnızca, ama sanat bizi insan kılmıştır" (Shiller, 2001). İnsanoğlu yaşadığı çevre ile sarmalanmıştır. O çevrede şekillenir tüm düşünce yapısı. Bu şekillenme ile büyür, kendi potansiyelinin farkına varır ve bir anlamda kendisini var eder. Sanatçılar bu kendini var edebilme dürtüsünde başka bir dil kullanma yetisine sahip bireylerdir. Ezici'ye (2005) göre sanatçı, hayal kurma yetisi olan, bir duygu ve duyarlılık gücü bulunan kişidir. Ancak onun kesin bir tanımlamayla sanatçı niteliğine bürünmesini sağlayan algılama biçimi onun özgünlüğüdür. Bu anlayışla, her sanatçı kendi çevresine, kültürüne ait birikimlerini yeteneği ile doğru orantılı olarak eserlerine yansıtır.

Hasan Pekmezci, 1945 yılında Konya-Beyşehir-Üzümlü'de dünyaya gelmiş o çevreyle kişiliği şekil almıștır. Daha çok küçük yaşlarda eğitime olan ilgisi çevresi tarafından fark edilmiş iyi bir eğitim alma ve kendisini var edebilme sürecinde kendisine destekolunmuştur. Pekmezci, sahip olduğu potansiyelin bulunduğu çevre tarafından desteklenmiş olmasının karşılığını zaman içinde yaşadığı farklı çevrelerde oluşturduğu farkındalık algısıyla yanıtlar. Onun eserlerindeki çiçekler, kuşlar, ağaçlar doğa içerisinde farklı bir duygu derinliği ile gözlerimize yansır. Sanatçı bakmakla görmek arasındaki derin farkın peşindedir. Ayaydın'a (2016) göre her insanın doğup büyüdüğü yer onlar için bir yer edinir. Sanatçının yaşadığı bu yer edinme duygusu daha somut şekillenir. İnsanlar bakar ancak sanatçlar görürler.

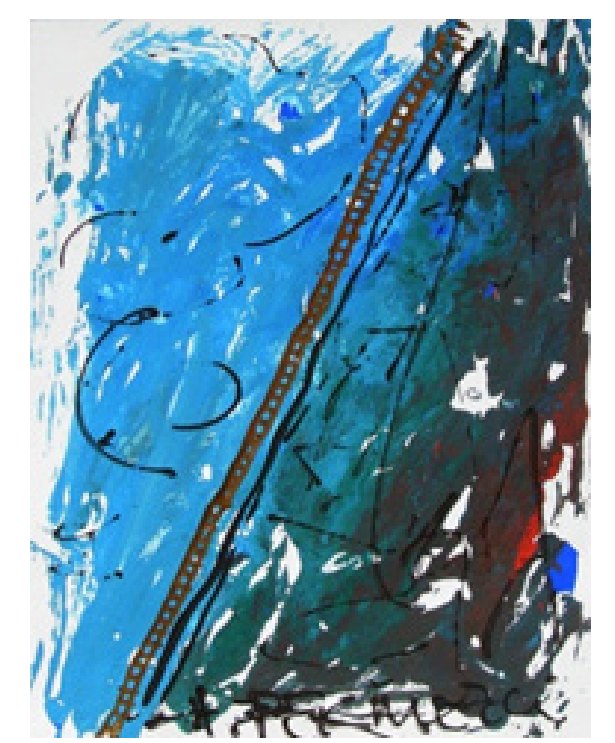

Resim I. Hasan Pekmezci, Doğa, 2006, D.Ü.Y.B., $50 \times 35$ cm
Doğanın somut nesneleri sanatçının onu yorumlama tarzıyla değişir/ dönüşür. Theo Van Doesburg "Doğayı biçimlerinden soyutlayın, o zaman onun ruhuna erişirsiniz" düşüncesinin bir örneğidir Pekmezci'nin çalışmaları (Ayaydın,2016:67). Doğa isimli çalışmasına baktığııızda o mavi gökyüzü tanıdık gelir (Resim 1). Yer ve gökyüzü ayrımındaki diyagonal merdiven sizi bir yolculuğa çă̆ııır ve izleyicide bilindik bir manzara duygusu yaratır. Diğer bir taraftan bilmediğiniz bir dünyayı tecrübe ediyormuşsunuz duygusu sizi sarmalar. Bu Pekmezci'nin yaratmış olduğu "kendi doğa" sına izleyiciyi davet etme yoludur. Pekmezci'ye göre:

Bir çiçek resmi yapan insanın o çiçeğin içine burnunu sokması, yaprakları arasında gezinmesi, dokunma duygusuyla onun doyumunu alabilmesi gerekli. Değilse yapılacak çiçek, teknik bir çizimden öteye gidemez. Botanikçiler bunun alasını yapmaktadır. Örneğin bir insanı çizerken; onun etiyle, kemiğiyle, bütün yaşamsallığılla, canlıı̆̆ıla, ruhuyla, iletişim kurmadan çizilecek bir insan resmi de yine anatomi çizimcilerinin yaptığı bir eylem olarak kalacaktır. Sanatçı bunların hepsini duyumsayabilen, içinde, yüreğinde, beyninde kıvılcımlar oluşturabilen kişidir. Ancak böyle olursa yaptığı da sanat olur. Çünkü sanatçı, resmine konu edindiği her şeyin özüne, gizine inmesini bilen ve bunu anlatıma dönüştürebilme gücüne sahip olan insandır (Saydam, 2006: 65).

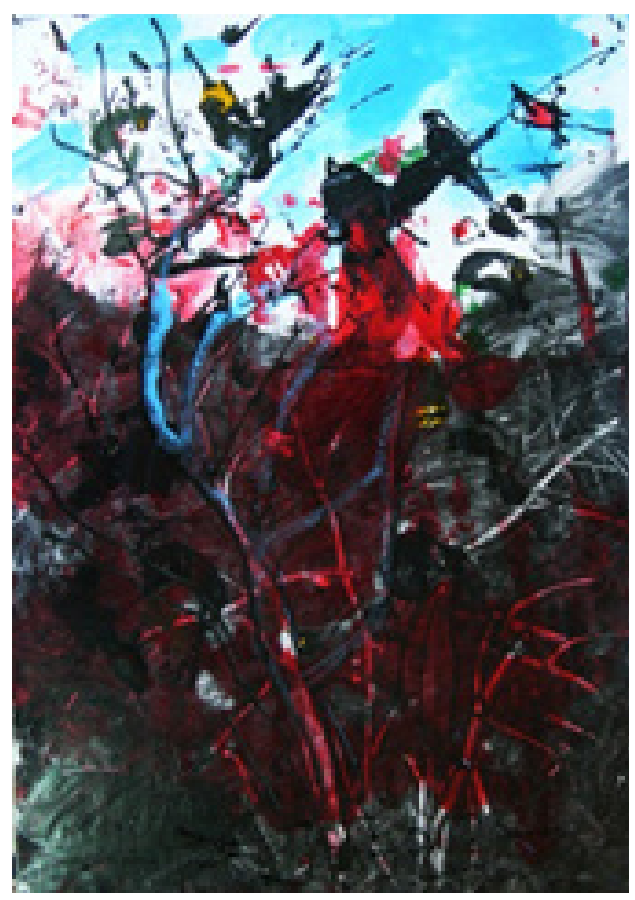

Resim 2. Hasan Pekmezci, Kuşlar, 2004, D.Ü.Y.B., $35 \times 50 \mathrm{~cm}$ 
Aynı mantıkla 2004 yılı Kuşlar isimli çalışmasında cıvıltıları duyabilirsiniz. Resmin üst kısmındaki mavi renk temiz bir gökyüzü kişinin psikolojisin doğrudan etkiler (Resim 2). Çoruhlu çalışmasında Pekmezci'nin mavi rengi kullanmasındaki anlamı şöyle dile getirir:

Bir anlamda gökyüzünü işaret etmek için kullandığı mavi rengin hâkimiyeti psikolojik olarak derinliği, sonsuzluğu, yalnızlığı ve hüznü çağrıştırmaktadır. Isşte tam da bu nedenle mavi rengi tercih eden sanatçı bu rengin izleyicinin algısında yoğun bir duygulanım yaratmasından faydalanmıştı. Çünkü mavi koyulaştıkça yani siyaha yaklaşıtıkça insanın iç dünyasındaki derinliklere inerek keder ve hüzün gibi duyguları açığa çıkartarak izleyiciyi daha da içine almaktadır (Çoruhlu, 1995).

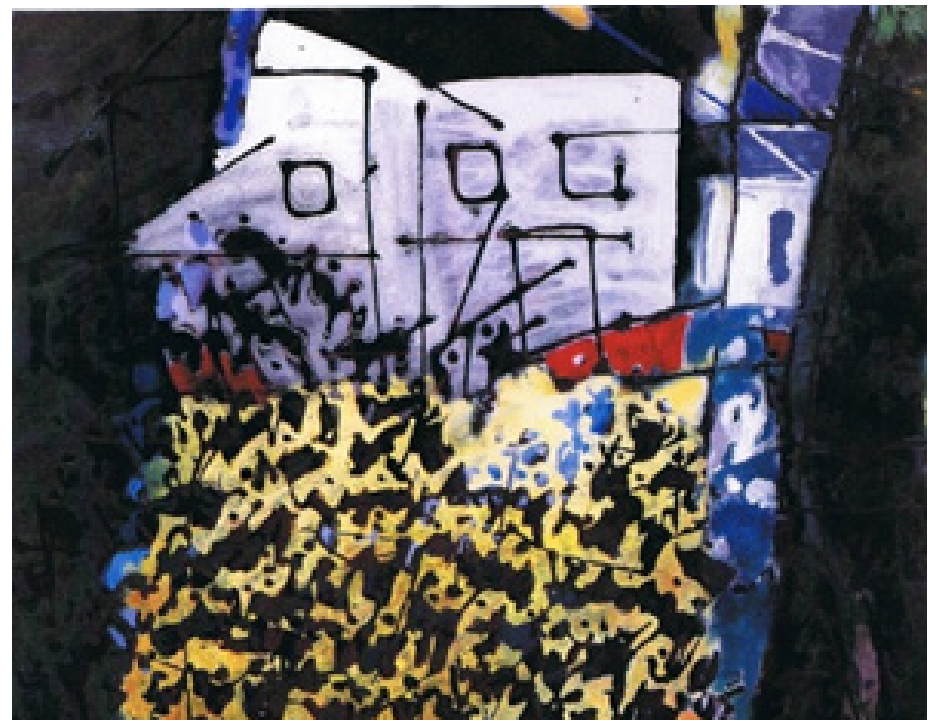

Resim 3. Hasan Pekmezci, Yığınların Özlemi, 1992, T.Ü.Y.B., $43 \times 50$ cm.

Pekmezci yaşadığı ülkenin toplumsal yapısını özümsemiş bir sanatçıdır Düz'e (2010) göre "sanatı yaratan emekte mutlaka bir düşünce vardır". Kent ve kırsal yaşama dair farklılıklar Pekmezci'nin düşüncelerinden önce duygularına yansır ve sonrasında bu duyguları yüzeye yansıtır. Kent yaşamına dair kalabalık insan topluluklarının yanı sıra yalnızlaşan bireyselleşen insanları konu edinen sanatçı çok yönlü fırça darbeleri ve oluşturduğu renk lekeleri ile insanın duygu durumunu somutlaştırmaktadır. Sanatçı için çevreyi gözlemlemek en büyük beslenme kaynağıdır. Konu olarak, teknolojinin insan ve topluma baskısını, çarpık kentleşme olgusu, çevre sorunlarını işlenmekte ve vurgulamaktadır. İnsanın, kent, doğa ve teknoloji karşısındaki ezikliğini, bu eziklikten kurtulmanın çaresini, güzelliğini, sevincini, korkusunu ve acısını paylaşmakta olduğunu söylemektedir sanatçı (Sertcan, 1992). Pekmezci:

Bazen Kızılay civarındaki binaların üstüne çıkıp alttaki kümelere bakmayı çok severim. İnsan, mimarı yapı, teknoloji konularını incelediğim dönemde epeyce fotoğraf çektim. İlk baktığınızda bir kalabalık vardır, ama insanın cismi pek yoktur. Dikkatle incelediğimizde hareketleriyle birlikte tek tek seçilmeye başlar. Bu belk bilinçaltına yerleşmiş bazı şeylerin anlatımı olabiliyor der (Saydam, 2006: 46)

Yığınların Özlemi isimli çalışması parçalara bölünmüş bir kompozisyonda soyut insan figürlerinin kent yaşantısı içerisinde olduğu görülmektedir (Resim 3). Pekmezci bu resminde ana renklerin dağılımında dengeli bi yaklaşım benimsemiştir. En geniş alanlardan olan sarı üzerinde yer alan soyut insan figürlerini resmin odağına koyarken en küçük alanları oluşturan kırmızı insanların resmin üst kısmında yer alan binalara bağlanmasında bir yardımcı görevdedir. Kompozisyon mavi rengi arka plana atarken yanlardaki siyahlar ilginin dağılmadan resmin bütününe yayılmasını sağlamaktadır.

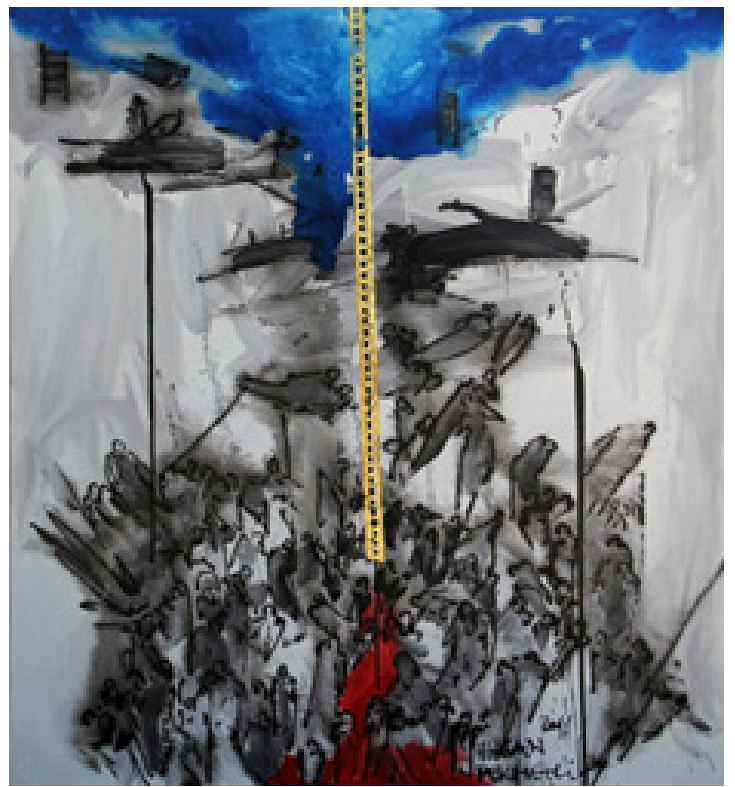

Resim 4. Hasan Pekmezci, Insanlarımız, 20II, T.Ü.Y.B., II0xI10 cm

Sanatçının insan yığınlarını farklı bir şekilde ele aldığı diğer bir resim 2011 yılında yapmış olduğu İnsanlarımız isimli eseridir (Resim 4). Burada dikkat resmin merkezine çekilmektedir. Tam ortada yukarı doğru uzanan sar merdiven bu merkezi bakışı güçlendirmektedir. Gri ve tonlarının baskın 
olduğu çalışmada iki ana renk (kırmızı ve mavi) birbirine bağlama görevi insan yığınları ile sağlanmaktadır. Pekmezci kırmızı gibi aktif bir rengin kullanımında oldukça titizdir. Onun için en önemli olan resmin konusudur ve hiçbir biçim ya da rengin konunun önüne geçmesine izin vermez. Sanatçının ortaya koyduğu bu renk ve biçim dengelerinin kusursuzluğu onun ustalı̆ıının bir yansımasıdır.

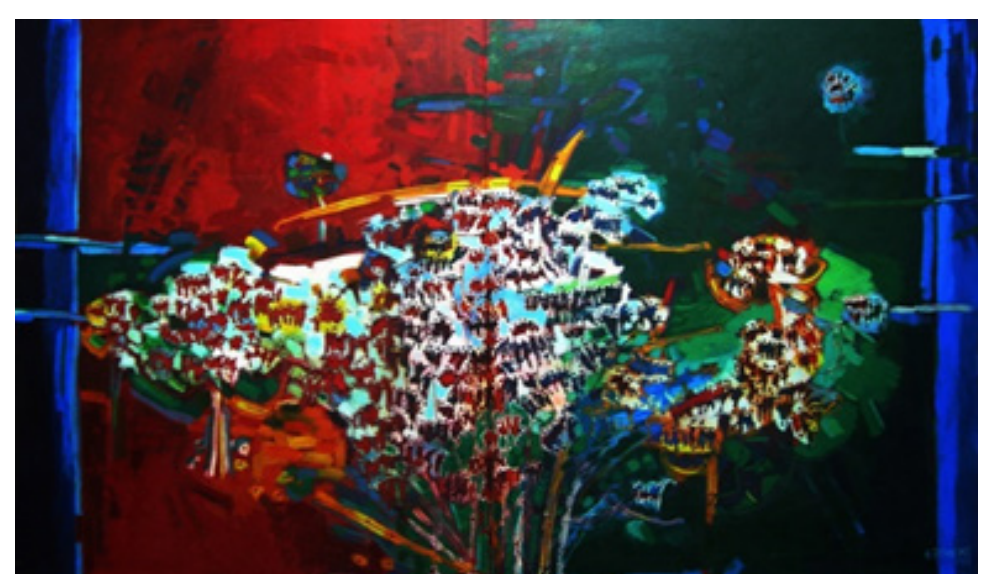

Resim 5. Hasan Pekmezci, Çiçek Gibi, 1982, T.Ü.Y.B., $120 \times 200 \mathrm{~cm}$

Siire ve edebiyata da meraklı olan sanatçının birçok şiiri ve öyküsü bulunmaktadır. "Bence sanatın bir alanıyla ilgilenip diğerlerine sırını dönmek, bir çeşit at gözlüğüyle görmek, bakmak anlamına gelir" söylemiyle konuya dair görüşünü ortaya koymuştur (Saydam, 2006: 41). Çiçek Gibi adlı eserinde o şiirsel anlatıyı görmeniz mümkündür (Resim 5). Pekmezci sanatın diğer alanlarıyla kurduğu ilişkinin benzerini resim teknikleri ile de kurmaktadır. Farklı tekniklerin yarattığı etkileri keşfetmek ve yeni teknikler geliştirmek onun en bilindik uğraşlarından biridir. Bu sebeple anlatmak istediği duygu ve düşünceyi ifade edebilecek teknik bilgi ve donanıma sahip olmanın rahatı̆ğ ile eserlerini üretir. Pentür ve serigrafiyi hayatının bir parçası haline getiren Pekmezci; sanat üretme sürecinde küçük-büyük; kağıt-tuval ayrımı yapmadan üretir. Bunun yanında sanatçı, sanat eserinin oluşumu sırasında, tuvalin üzerine çizmeden, direkt olarak fırça ile resme başlar (Sertcan, 1992). Hasan Pekmezci, sanatın gizemi ve sanatçıyı durmadan üretmeye sevk eden özelliği hakkındaki düşünceleri şöyledir:

Benim için önemli olan; İnsan yaşamı kısa. Doğum ile ölüm arasında kısacık bir çizgi. Tarihsel süreç içinde hiç önemi olmayan bir zaman dilimi. Sanatın bu çizgiyi sonsuzluk çizgisine dönüştürebilmek özelliği ya da gizi beni sanata bağlayan en önemli etmen olmuştur. Sanat, ölümsüzlük çizgisidir. Sanata bakışımızı belirleyen, yaşamımızı yönlendiren, sanatsal etkinliğimize ivme veren bu inanışıı (Saydam, 2006: 42).

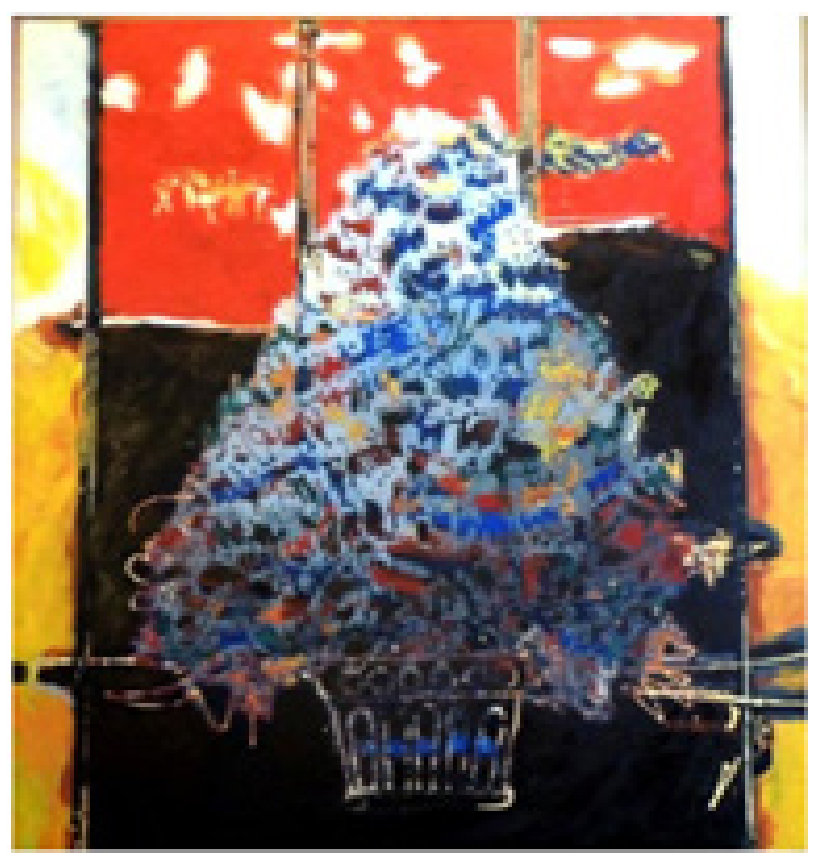

Resim 6. Hasan Pekmezci, Bir Çiçek Gibi, 1982, T.Ü.Y.B., $97 \times 90$ cm.

Budapeşte Güzel Sanatlar Müzesi Daimi Koleksiyonu

Resimlerinde yaşamından, anılarından, dünyayı anlama ve sorgulama bilincinden kaygılar taşımaktadır. Yaşam Merdivenleri, Dağlar, KuşlarKafesler, Kuş Yuvaları, Yaşam Labirentleri, Ey Zaman serisi, Gülhatmi Çiçekleri gibi resim serileri Pekmezci'nin yaşam öykülerinin görsel ifadesidir (Batur, 2016: 200). Özpolat'a (1992) göre Pekmezci'nin resimlerinde işlediği konular, yalnızca Türk toplumunun sorunları değil, tüm dünyanın ortak sorunu, ortak kaderi olması sebebiyle evrensel olduğu görüșündedir. Sanatçı 1982 yılında yapmış olduğu Çiçek Gibi isimli çalışmasının bir farkı versiyonunu 1985 yılında Avrupa Kültür Forumu kapsamında açılan ve 25 ülkeden, 125 sanatçının davet edildiği Budapește sergisinde sergilemiștir. Bu sergide Bir Çiçek Gibi isimli yağlıboya tablosu Macaristan Çağdaş Sanatlar Müzesi'nin daimi koleksiyonuna alınmıstır (Resim 6). Kayahan'a (2013) göre, Budapeşte Güzel Sanatlar Müzesi'nde alanında uzman bir Türk sanatçısının/akademisyeninin eserinin yaklaşık 30 yıldır yer alıyor olması ülkemiz ve sanat tarihimiz açısından büyük bir onurdur. 


\section{Sonuç ve Değerlendirmeler}

Sanat bir anlamda insanın kendisini ifade etme biçimidir ve bireysel/ toplumsal değişimler sanat alanında da yeni oluşumlara olanak tanımışıtır. Bu anlamda geçmişin geleneğinden beslenen ve geleceğin kurgusu içinde filizlenen sanat ve sanatçı için üretim, dinamizmini hiç kaybetmeden bir yaşam alanı haline gelmektedir.

Bu yaşam alanı Çağdaş Türk sanat ve eğitimi açışından bir yapı taşı olan ve 50. sanat hayatını kutlayan Hasan Pekmezci'nin sanatında ve kișiliğinde kendisini gözler önüne sermektedir. Pekmezci'nin sanatı ve eğitimciliği her zaman insanı/bireyi özne konumunda tutmaktadır. Çünkü O'na göre ne sanat ne de sanat eğitimi yaşamdan ve bireyden kopuk olamaz. Tam da bu anlayışla Pekmezci, bireysel üretimlerinde de yaşamı, doğayı, insanları, memleket manzaralarını vb. resimlerinde çeşitlendirmiş̧tir.

Eğitimciliğinin ve aktif sanat hayatının yanı sıra uzun yıllar öğretim üyesi olarak çalıştığı üniversitelerde de öğrencilerine verdiği akademik bilgilerin yanı sıra insancıl yaklaşımı sayesinde öğrencilerini her zaman etraflarında olup bitene duyarlı olmaya yöneltmiştir. Sanatçının bu tutumu sanat eğitimi alanında öğrencilerinin kendisinden sadece pentür, baskı resim, sanat tarihi vb. alanlarında değil aynı zamanda yaşama dair bir şeyler öğrenebilmek için meraklı zihinlerle beklediği keyifli atölye ortamlarını yaratmıştır.

Hasan Pekmezci'nin başarılı sanatsal/akademik kişiliğinin yanı sıra bireysel duyarlılığı sayesinde hem alandan hem de alandan olmayan birçok kişinin sanata ve sanatçıya dair bakış açısını değiştirmiş ve sanatın müzik, şiir, bale, opera vb. gibi her alanına dair bir duyarlılık kazanmasını sağlamıştır.

\section{Kaynakça}

Ayaydın, A. (2016). “Sanatın Doğası, Doğanın Sanatı ve Günümüz Sanat Eğitiminde Doğanın Yeri”, 2I. Yüzyılda Eğitim ve Toplum Dergisi, (14), 65-74.

Batur, M. (2016). “Türk Resminde Günlük Yaşam Konulu Resimlerde Sembol”, Mehmet Akif Ersoy Üniversitesi Sosyal Bilimler Enstitüsü Dergisi, 8(14), I93-2II.

Çoruhlu, Y. (1995). Türk Sanatı'nda Hayvan Sembolizmi. Istanbul: Seyhan Kitap.

Düz, N. ( 2010). “Çevrenin Sanatçı Yaratııılı̆ına Etkileri ve Sanat Eğitimi”, Akademik Bakış Dergisi, Sayı:. Web: http://www.akademikbakis.org/eskisite//9//2.htm adresinden I5 Nisan 2018'de alınmıştır.

Ezici, A. K. (2005). "Sanatçının Kişiliği ve Yaratma Psikolojisi”, Anatolian Journal of Psychiatry, Sayı 6, I22-127.

Kayahan, Z. (2013). “Bir Tutku Müzesi; Budapeşte Güzel Sanatlar Müzesi”, Atatürk Üniversitesi Güzel Sanatlar Fakültesi Sanat Dergisi, Sayı 23, 85-93.

Özpolat, S. N. (1992). Baskı Resim Sanatçısı olarak Hasan Pekmezci. Gazi Üniversitesi Sosyal Bilimler Enstitüsü (Ders Ödevi) Ankara.

Saydam, I. H. (2006). Günümüz Sanat Eğitimi ve Sanat Eğitimi Içinde Prof. Dr. Hasan Pekmezci'nin Yeri, Yayımlanmamış Yüksek Lisans Tezi, Selçuk Üniversitesi, Konya

Schiller, F. (200I). Insanın Estetik Eğitimi Üzerine Bir Dizi Mektup (çev: G.Aytaç) Kültür Bakanlığı Yayınları.

Sertcan, Ş. (1992). Hasan Pekmezci ve Sanatı. Yayımlanmamış Lisans Tezi, Ankara Üniversitesi Dil ve Tarih Coğrafya Fakültesi, Ankara.

\section{Görsel Kaynakları}

Resim I: http://www.artsnt.com/hasan_pekmezci.php

Resim 2: http://www.artsnt.com/hasan_pekmezci.php

Resim 3: Saydam, I. H. (2006). Günümüz Sanat Eğitimi ve Sanat Eğitimi İçinde Prof. Dr. Hasan Pekmezci'nin Yeri, Yayımlanmamış Yüksek Lisans Tezi. Selçuk Üniversitesi, Konya

Resim 4: http://www.artsnt.com/hasan_pekmezci.php

Resim 5: https://tr.wikipedia.org/wiki/Dosya:Hasan.Pekmezci.1982.jpg

Resim 6: Kayahan, Z. (20/3). "Bir Tutku Müzesi; Budapește Güzel Sanatlar Müzesi”, Atatürk Üniversitesi Güzel Sanatlar Fakültesi Sanat Dergisi, Sayı 23, 85-93. 